\title{
In community-dwelling women frailty is associated with imminent risk of osteoporotic fractures
}

\author{
P. Bartosch ${ }^{1,2}$ (I) $\cdot$ L. Malmgren ${ }^{1,2,3}$ (D) J. Kristensson ${ }^{4,5}$ (D) F.E. McGuigan ${ }^{1,2}$ (D) $\cdot$ K.E. Akesson ${ }^{1,2}$
}

Received: 15 November 2020 / Accepted: 9 February 2021 / Published online: 4 March 2021

(C) The Author(s) 2021

\begin{abstract}
Summary Frailty reflects an accelerated health decline. Frailty is a consequence of fracture and contributes to fracture. Greater frailty was associated with higher fracture risk. Frail women were at immediate risk (within 24 months) of a hip or major fracture. Fracture prevention could be improved by considering frailty status.

Introduction Frailty encompasses the functional decline in multiple systems, particularly the musculoskeletal system. Frailty can be a consequence of and contribute to fracture, leading to a cycle of further fractures and greater frailty. This study investigates this association, specifically time frames for risk, associated fracture types, and how grade of frailty affects risk.

Methods The study is performed in the OPRA cohort of 1044, 75-year-old women. A frailty index was created at baseline and 5 and 10 years. Women were categorized as frail or nonfrail and in quartiles (Q1 least frail; Q4 most frail). Fracture risk was assessed over short (1 and 2 years) and long terms (5 and 10 years). Fracture risk was defined for any fracture, major osteoporotic fractures (MOFs), and hip and vertebral fracture, using models including bone mineral density (BMD) and death as a competing risk.

Results For women aged 75, frailty was associated with higher risk of fracture within 2 years (Hip SHR adj. $_{3.16}(1.34-7.47)$ ) and MOF (2 years SHR adj. $_{1.88}(1.12-3.16)$ ). The increased risk continued for up to 5 years (Hip SHR adj. 2.02 (1.07-3.82)); (MOF SHR $\left._{\text {adj. }} 1.43(0.99-2.05)\right)$. Grade of frailty was associated with increased 10-year probability of fracture $(p=0.03)$. Frailty predicted fracture independently of BMD. For women aged 80, frailty was similarly associated with fracture.

Conclusion Frail elderly women are at immediate risk of fracture, regardless of bone density and continue to be at risk over subsequent years compared to identically aged nonfrail women. Incorporating regular frailty assessment into fracture management could improve identification of women at high fracture risk.
\end{abstract}

Keywords BMD $\cdot$ Community dwelling $\cdot$ Fracture $\cdot$ Frailty $\cdot$ Women

K.E. Akesson

kristina.akesson@med.lu.se

1 Department of Clinical Sciences Malmö, Clinical and Molecular Osteoporosis Research Unit, Lund University, 214 28 Malmö, Sweden

2 Department of Orthopaedics, Skåne University Hospital, 205 02 Malmö, Sweden

3 Department of Geriatrics, Skåne University Hospital, Malmö, Sweden

4 Department of Health Sciences, Proactive an integrated care research unit, Faculty of Medicine, Lund University, 22100 Lund, Sweden

5 The Institute for Palliative Care, Lund University and Region Skåne, Lund, Sweden

\section{Introduction}

Osteoporosis, which causes low bone mass and microarchitectural deterioration, is responsible for 3.5 million fractures annually in Europe [1]. These fragility fractures occur typically at the hip, wrist, and vertebra and are a significant cause of disability, pain, and reduced quality of life [2]. Fractures are also associated with mortality [3, 4]. In addition to the personal toll, they account for increased health care costs, particularly after hip fracture [5].

As a consequence of aging, and the inevitable functional decline in the musculoskeletal system, almost every second, woman in Sweden will suffer a fracture by the age of 80 [4]. Since demography changes towards an elderly population [6], the $50 \%$ lifetime fracture risk for women over the age of 50 makes prevention of osteoporotic fracture not only a challenge but a must. 
One way to identify individuals at high risk of osteoporotic fracture could be frailty. Frailty encompasses the functional decline in multiple physiological systems, with perhaps the most dramatic changes in the musculoskeletal system [7, 8]. Frailty is both a consequence of and a contributing factor to fracture. Consequently, this association can lead to a vicious cycle of further fractures and greater frailty $[9,10]$ and a wide range of adverse outcomes [8].

Fracture prevention, whether primary or secondary, is an important aspect for successful aging [11], and one of the most significant obstacles is the difficulty in correctly identifying those at high risk of fracture [4]. Of the standard tools, neither bone density measurements nor fracture risk assessment by FRAX can fully capture and adequately identify all those at risk. In particular, there are limitations when applied in the very old [12]. With these limitations, new aids to improve risk assessment are needed; one such possibility is to evaluate frailty.

Although earlier studies have investigated frailty and fracture $[13,14]$, few have been performed in cohorts specifically designed to address osteoporosis-related outcomes. The knowledge gaps include whether frailty can independently predict fracture and if so which fracture types and over what time periods. In older individuals, hip fracture is the predominant fracture of interest, but can other types of fractures be predicted by frailty since these might precede a hip fracture? Furthermore, with advancing age, it is not known how frailty and fracture interact.

We have previously followed the progression of frailty over 10 years and reported that frailty is associated with osteoporosis, falls, and mortality in a population of communitydwelling elderly women $[15,16]$. In the present study, the overall aim was to explore the association between frailty and fracture. Firstly, we investigated the time frame over which a frail person is at increased risk, focusing on imminent risk, i.e., over 1 and 2 years and longer term, over 5 and 10 years. Secondly, we investigated if frailty is independently predictive of specific fracture types with advancing age. Thirdly, we investigated if early stages of frailty and progression interact with fracture risk. Ultimately, this knowledge may contribute to the understanding of how frailty assessment can serve as an integral part in fracture prevention protocols.

\section{Materials and methods}

\section{Subjects}

The Osteoporosis Prospective Risk Assessment (OPRA) cohort is an observational study designed to study risk factors related to bone health. Community-dwelling women, 75 years old (75.2 \pm 0.2 years), were randomly selected, without exclusion criteria, from the population register for Malmö, Sweden
[17]. Of those invited, 1044 attended baseline investigation (1995-1999), 67\% attendance rate. At follow-up, 715 attended (age $80.2 \pm 0.2$ ) at 5 years and 382 (age $85 \pm 0.1$ ) at 10 years. Reasons for nonparticipation have been previously described in full [18].

At each visit, detailed investigations were performed: physical assessment (balance, gait, and muscle strength), biomarkers, and measurements of femoral neck bone mineral density (BMD) together with questionnaires to capture information related to lifestyle, health, and other risk factors $[15,17]$.

Using the unique personal identification number allocated to every Swedish citizen, date of death was acquired from the Swedish National Population Register (October 2012, when the maximum age of those women still alive was 91.5 years).

All procedures performed were in accordance with the ethical standards of the regional ethical review board in Lund (Dnr: 2014804), and the study was performed according to the principles of the Helsinki Declaration. All women provided written informed consent.

\section{Assessment of frailty}

A deficit accumulation frailty index (FI) was constructed adhering to the principles suggested by Searle et al. [19], i.e., all variables were associated with health, increased with age, did not saturate too early, and covered a wide range of domains. Briefly, all continuous and categorical variables were reclassified into the range 0.0 and 1.0 and then summed and divided by the numbers of variables included (Online Resource 1). The thirteen variable index, including treatment of missing values, has been described previously [16]. The index represents "deficits in health," where a higher score indicates higher frailty. The index of frailty was calculated for each age $(75,80$, and 85). An empirical threshold of $\geq$ 0.25 was used to define frail individuals $[16,20,21]$.

\section{Fractures}

Incident fractures were prospectively followed until October 2012 (up to 15 years) through the X-ray files at the Radiology Department, Malmö, Skåne University Hospital [18]. Information loss during follow-up was exceptionally low since the Department of Orthopaedics is the sole unit treating fractures in the catchment area. Fractures resulting from pathology and high energy were excluded. Fractures occurring prior to inclusion (specifically, between ages 50 and 75) were also registered [22].

\section{Statistical analyses}

Descriptives for continuous variables are reported as mean and standard deviation (SD) or median and interquartile range 
(IQ) where appropriate. Categorical variables are reported as number $(n)$ and percentage $(\%)$.

Frailty was analyzed as categories "frail" $(\geq 0.25)$ or "nonfrail" (< 0.25$)$ and in quartiles (Q1 least frail; Q4 most frail) to visualize progression of frailty and changes in fracture risk. Fractures are reported as any fracture, major osteoporotic fractures (MOFs) as defined by FRAX (http://www.shef.ac. uk/FRAX), and hip and vertebral fracture.

The temporal association between frailty and fracture was explored in different time frames. From age 75, we estimated short-term (1 and 2 years) fracture risk (i.e., frailty at age 75 and incident fractures between ages 75-76 and 75-77) and long-term ( 5 or 10 years) risk (fractures between ages 75-80 and 75-85). To evaluate this association in the very old, we then "reset" baseline and, based on frailty at age 80 , estimated fracture risk over the same time frames.

Demographic characteristics of frail/nonfrail women were compared using Student's T-test and chi-square or MannWhitney $U$ test for nonparametric distributions.

Fracture incidence was defined as the number of women sustaining at least one fracture during the specified time frame. Incidence rate is presented as number of fractures per 1000 person-years, calculated using all registered fractures. Incidence rate ratios (IRRs) with $95 \%$ confidence intervals (95\% CI) were estimated by Poisson distribution to compare fracture rates between frail/nonfrail women.

To investigate the association between frailty and fracture with death as a competing event, we estimated the probability of fracture, calculated as a cumulative incidence function (CIF) with Gray's test to assess statistical significance. To predict fracture risk, we used the model proposed by Fine and Gray [23] estimating proportional subdistribution hazard ratios (SHR) and 95\% CI for a first fracture. To determine if frailty independently predicts fracture risk, BMD was included as a covariate. Subgroup analysis further assessed the additive effect of smoking.

The study is estimated to have $>80 \%$ power to detect a 1.45 difference in relative risk (RR) for any fracture (alpha $5 \%$ ), between frail and nonfrail women. This is based on the 5 -year incidence of any fracture $(19.1 \%)$ in nonfrail women from the cohort. However, acknowledging the limitations of post hoc power calculations [24], confidence intervals indicate the reliability of the associations. Analyses were performed using SPSS v25 and RStudio v1.2.5042 [25, 26]. $p<0.05$ was considered nominally significant.

\section{Results}

The characteristics of the OPRA cohort have been reported in detail previously [15], while those relevant to this study are shown in Table 1. On inclusion in the study at age 75 , the median FI of the population was 0.16 (range 0.01-0.74).
Almost one quarter $(23.5 \%, n=245)$ of the women were classified as frail ( $F I \geq 0.25)$. For women having sustained a fracture prior to baseline, about half of the individual variables comprising the FI differed between frail and nonfrail women, predominantly those related to musculoskeletal function, while there was no difference in disease incidence or biomarkers. Frail women had higher BMI, higher bisphosphonate and glucocorticoid usage, and more previous fracture and falls $(p<0.05)$.

At the end of the study (October 2012), half of the women $(50.2 \%, n=524)$ had sustained at least one fracture, and a quarter $(25.7 \%, n=268)$ had two or more fractures. Hip fracture occurred in $18.7 \%(n=195)$ of the population and $20.5 \%(n=$ 214) had at least one vertebral fracture. The total fracture incidence increased regardless of frailty status over the observation period; between 75 and $80(n=214)$, the incidence of a first fracture was $20.5 \%$ and between 80 and $85(n=177) 24.8 \%$.

The fracture incidence rate per 1000 person-years was higher among women who were frail at age 75 , for any fracture $(109.0$ vs. $80.8 ; p<0.01)$ and MOF (80.1 vs. $64.0 ; p<$ 0.01 ); reflected in an increased risk (IRRs 1.35 and 1.25), respectively. Hip fracture did not differ (23.1 vs. 18.0; $p=0.13$ ).

The distribution of fracture types in frail and nonfrail women is shown in Online Resource 2.

\section{Frailty at age 75 and short- and long-term fracture risk}

Since age is an important factor for the elderly, we firstly investigate the short-term time frame and risk within the first 2 years. For a 75 -year-old woman who is frail, the risk of hip fracture is elevated already within the first year compared to identically aged, nonfrail women (SHR 3.94, (1.20-12.9)). This is reflected in the proportion of women who fractured (2.4\% vs. $0.6 \% ; p=0.014$ ) (Table $2 \mathrm{~A}$ and Supplementary Table 2). Adjustment for BMD did not significantly alter this association (SHR adj. $3.75(1.11-12.71))$. The risk of hip fracture continued to be elevated at two years (SHR 3.04 (1.34$6.88)$ ). Indeed, the proportion of frail women who fractured was more than doubled compared to nonfrail (4.5\% vs. $1.8 \%$; $p=0.005)$. The frail also had a higher risk of any fracture and MOF within the first 2 years, SHR 1.70 (1.11-2.60) and 1.89 (1.17-3.06), respectively (Table 2A and Fig. 1a). Adjusting for BMD did not change these results. Being a current smoker and frail further increased the risk of fracture (Any HR 2.51 (1.15-5.48); MOF HR 2.89 (1.24-6.76); Hip HR 3.70 (1.0413.1) compared to non-smoking frail women) while not apparent for the nonfrail. The proportion fractured were $13.1 \%$ vs. $7.9 \%(p=0.014)$ for any fracture and $10.6 \%$ vs. $5.8 \%$; $(p=$ 0.009) for MOF (Online Resource 3 ).

In the 5-year perspective, frailty continues to associate with fracture (Table 2A and Table 3A). For hip fracture, the frail 
Table 1 Characteristics of nonfrail and frail women at age 75

\begin{tabular}{|c|c|c|c|c|}
\hline \multirow[t]{2}{*}{ All variables at 75 years } & \multicolumn{2}{|c|}{$\begin{array}{l}\text { Nonfrail }(<0.25) \\
n=799\end{array}$} & \multicolumn{2}{|c|}{$\begin{array}{l}\text { Frail }(\geq 0.25) \\
n=245\end{array}$} \\
\hline & Mean & $\mathrm{SD}$ & Mean & $\mathrm{SD}$ \\
\hline Frailty index (FI) & 0.14 & $(0.05)$ & 0.36 & $(0.10)$ \\
\hline BMI $\left(\mathrm{kg} / \mathrm{m}^{2}\right)$ & 26.0 & $(3.88)$ & 27.0 & $(5.05)$ \\
\hline Femoral Neck BMD $\left(\mathrm{g} / \mathrm{cm}^{2}\right)$ & 0.764 & $(0.114)$ & 0.770 & $(0.152)$ \\
\hline \multirow[t]{2}{*}{ Femoral Neck (T-score) } & -1.80 & $(1.12)$ & -1.76 & $(1.27)$ \\
\hline & No. & $(\%)$ & No. & $(\%)$ \\
\hline Current smoker & 107 & $(13.5)$ & 38 & $(15.8)$ \\
\hline Bisphosphonate user & 20 & $(2.5)$ & 13 & $(5.3)$ \\
\hline Glucocorticoid user $^{\mathrm{a}}$ & 49 & $(6.1)$ & 29 & (11.9) \\
\hline No. of women with prior fractures between 50 and 75 & \multicolumn{2}{|l|}{$n=792$} & \multicolumn{2}{|l|}{$n=239$} \\
\hline At least one fracture & 278 & $(35.1)$ & 105 & $(43.9)$ \\
\hline Major osteoporotic fracture & 174 & $(22.0)$ & 51 & $(21.3)$ \\
\hline Hip & 9 & $(1.1)$ & 5 & $(2.1)$ \\
\hline Radius & 146 & $(18.4)$ & 41 & $(17.2)$ \\
\hline No. of women who fell in previous 12 months $^{b}$ & \multicolumn{2}{|l|}{$n=693$} & \multicolumn{2}{|l|}{$n=221$} \\
\hline At least one fall & 146 & $(21.1)$ & 114 & $(51.6)$ \\
\hline No falls & 547 & $(78.9)$ & 107 & $(48.4)$ \\
\hline Deceased at end of study (2012) & 414 & $(51.8)$ & 184 & $(75.1)$ \\
\hline Deceased after 10 years & 190 & $(23.8)$ & 117 & $(47.8)$ \\
\hline
\end{tabular}

${ }^{\text {a }}$ Current or previous use for $>3$ months

${ }^{\mathrm{b}}$ Self-reported

75-year-old is at twice the risk compared to the nonfrail, even accounting for competing mortality (SHR 2.03 (1.13-3.64)) and similarly for incidence rate 17.5 vs. 8.1 per 1000 personyears. Overall, a greater proportion of frail women had at least one fracture at any site $(24.9 \%$ vs. $19.1 ; p=0.051)$, a higher fracture incidence rate (78.1 vs. 55.5 per 1000 person-years), and a higher risk even accounting for competing mortality. Vertebral fractures were more frequent in the frail $(9.4 \%$ vs. $5.3 \% ; p=0.019)$, and risk was higher (SHR. $1.83(1.10$
3.04)). With adjustment for BMD, the risk estimate just crossed below significance level (SHR adj. $_{1.75}(0.99-3.10)$ ). In the same time frame, the IRR was almost doubled for vertebral fractures (1.79 (1.14-2.76)) (Table 3A).

For a woman who is frail at age 75 , compared to the nonfrail, the cumulative incidence trajectories differ, with the greatest difference at 2 to 5 years (Fig. 1a). In a 10-year perspective, the probability of fracture continues to be elevated, although, with the extended observation period and
Table 2 Relative risk of fracture for frail women across time frames of 1,2 , and 5 years based on being frail at (A) age 75 and (B) age 80

\begin{tabular}{|c|c|c|c|c|c|c|}
\hline & \multicolumn{2}{|c|}{ 1-year risk } & \multicolumn{2}{|c|}{ 2-year risk } & \multicolumn{2}{|c|}{ 5-year risk } \\
\hline & $\mathrm{SHR}^{\mathrm{a}}$ & $95 \% \mathrm{CI}$ & SHR & $95 \% \mathrm{CI}$ & SHR & $95 \% \mathrm{CI}$ \\
\hline \multicolumn{7}{|l|}{ (A) Frail at age 75} \\
\hline Any & 1.55 & $(0.87-2.76)$ & 1.70 & $(1.11-2.60)$ & 1.38 & $(1.02-1.86)$ \\
\hline Major osteoporotic & 1.71 & $(0.90-3.25)$ & 1.89 & $(1.17-3.06)$ & 1.38 & $(0.99-1.93)$ \\
\hline Hip & 3.94 & $(1.20-12.9)$ & 3.04 & $(1.34-6.88)$ & 2.03 & $(1.13-3.63)$ \\
\hline Vertebral & 1.19 & $(0.38-3.74)$ & 1.88 & $(0.79-4.46)$ & 1.83 & $(1.10-3.04)$ \\
\hline \multicolumn{7}{|l|}{ (B) Frail at age 80} \\
\hline Any & 1.85 & $(0.95-3.59)$ & 1.59 & $(1.02-2.48)$ & 1.52 & $(1.13-2.04)$ \\
\hline Major osteoporotic & 1.89 & $(0.93-3.83)$ & 1.79 & $(1.12-2.86)$ & 1.53 & $(1.12-2.09)$ \\
\hline Hip & 5.43 & $(1.13-26.2)$ & 2.0 & $(0.91-4.39)$ & 1.48 & $(0.90-2.44)$ \\
\hline Vertebral & 1.86 & $(0.57-6.09)$ & 1.43 & $(0.63-3.24)$ & 1.97 & $(1.21-3.21)$ \\
\hline
\end{tabular}

${ }^{\text {a }}$ Subdistribution hazard ratios with reference category nonfrail. Frailty status was assessed at beginning of each period calculated (ages 75 and 80 ) 
a

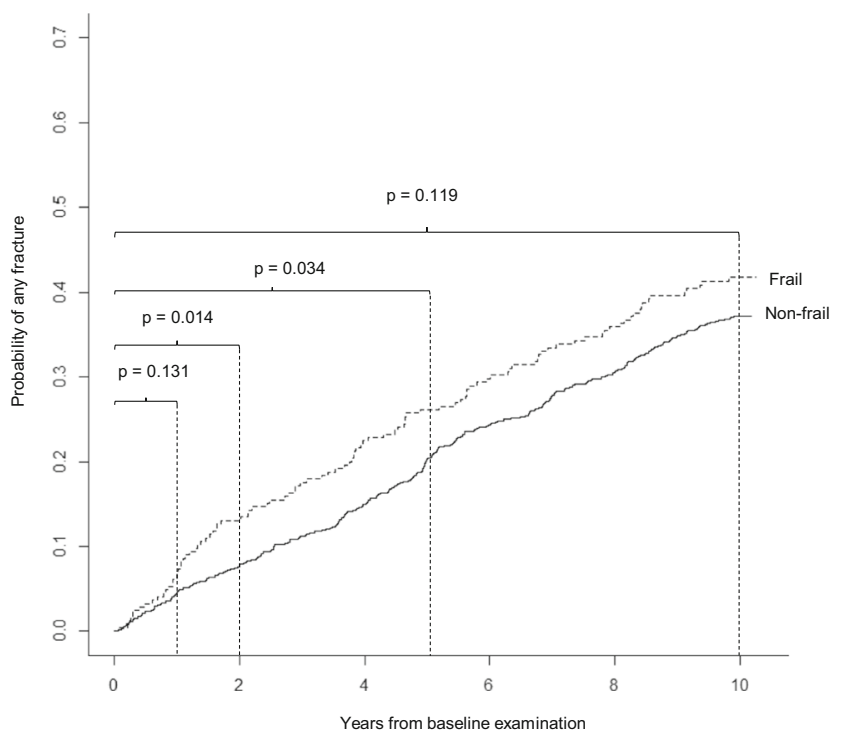

b

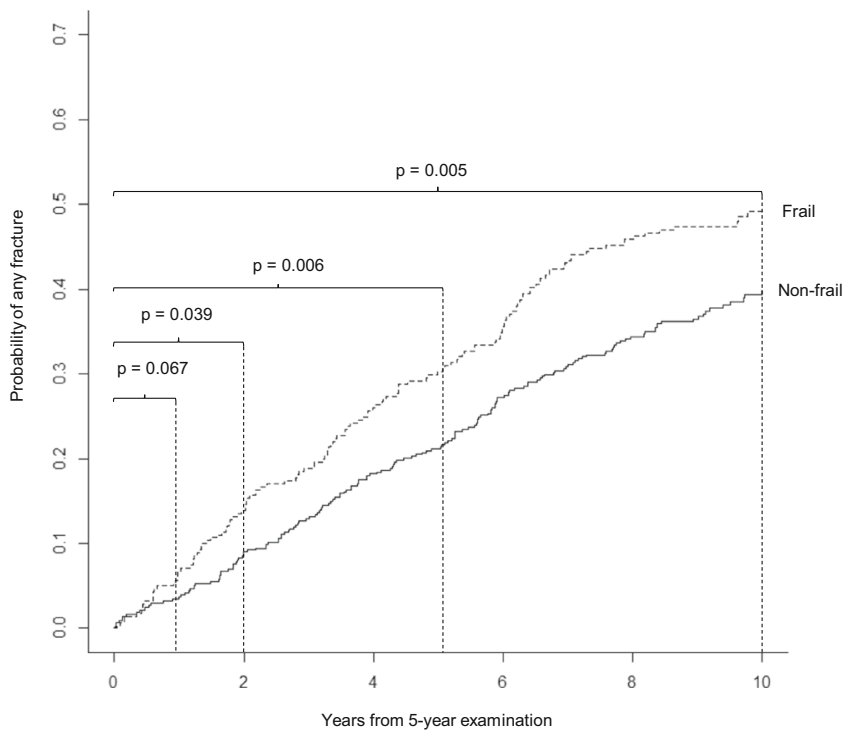

Fig. 1 Cumulative incidence of any fracture stratified by frailty status at $\mathbf{a}$ age 75 and $\mathbf{b}$ age 80 , calculated in the presence of the competing risk of death. Differences in cumulative incidence rates between frail and nonfrail categories were tested using Gray's test

advancing age, baseline frailty status does not discriminate the probability of fracturing as is obvious by the comparable slopes.

\section{Grade of frailty and fracture risk}

Quartiles were used to further categorize frailty; (Q1 range $\leq$ 0.11; Q2 0.12-0.16; Q3 0.17-0.24; Q4 $\geq 0.25$ ). There was a clear stepwise association between increasing frailty and the 10 year probability of a first fracture of any type (Q4 to Q1 (Gray's $p=0.03)$ ) (Fig. 2a). For vertebral fractures, a significant difference was seen already between Q1 and Q2 $(p=0.005)$.

The time difference in fracture accumulation between the least frail and most frail (Q1 and Q4) is 2.5 years for any fracture and 4.7 years for hip fracture, i.e., the fracture free time is longer in the least frail (Fig. 2a, b).

\section{Frailty at age 80 and short- and long-term fracture risk}

For an 80-year-old woman who is frail, the risk of hip fracture is also elevated (SHR $5.43(1.13-26.2)$ ), although the proportion who fractured during this first year was low $(2.5 \%$ vs. $0.5 \% ; p=0.017$ ) (Table 2B). The risk continued to be elevated at 2 years; hip fracture (SHR $2.0(0.91-4.39)$ ) while not reaching statistical significance, any fracture (SHR 1.59 (1.02-2.48)) and MOF (SHR 1.79 (1.12-2.86)).

In the 5-year perspective, although frailty is less predictive for hip fracture (SHR $1.48(0.90-2.44)$ ), it continues to be associated with a higher risk of any fracture (SHR 1.52 (1.13-2.04)), MOF (SHR 1.53 (1.12-2.09)) and for vertebral fractures (SHR 1.97 (1.21-3.21)). Adjusting for BMD did not change the results.

The incidence trajectories for women who were frail and nonfrail at age 80 are illustrated in Fig. 1b. The probability of any fracture continues to be elevated for up to 10 years in the frail compared to the nonfrail.

\section{Fracture leads to frailty}

Having analyzed how frailty influences the risk of future fracture, we next investigated how a prior fracture, from age 50 to the baseline investigation, influenced frailty at age 75 . Prior to the baseline, $37.1 \%(n=383)$ of the women reported a fracture between ages 50 and 75 . The mean frailty score was significantly higher compared to those with no prior fracture $(0.21$ vs. $0.18, p<0.01)$. Furthermore, women with a fracture between ages 50 and 75 and in both later age intervals (75-80 and 80-85) were more frail compared to those who remain fracture free throughout, from ages 50 to 85 ( 0.38 vs. $0.27, p=$ 0.038). On the other hand, among those with a prior fracture, but no new fractures up to the age of 85 , the frailty score was equivalent to those never experienced a fracture $(0.27$ vs. 0.27) (Fig. 3).

\section{Discussion}

This study of 75-year-old community-dwelling women indicated that frailty is an important, clinically feasible way to identify individuals at high fracture risk. Going beyond traditional risk factors such as BMD, frailty assessment takes a 


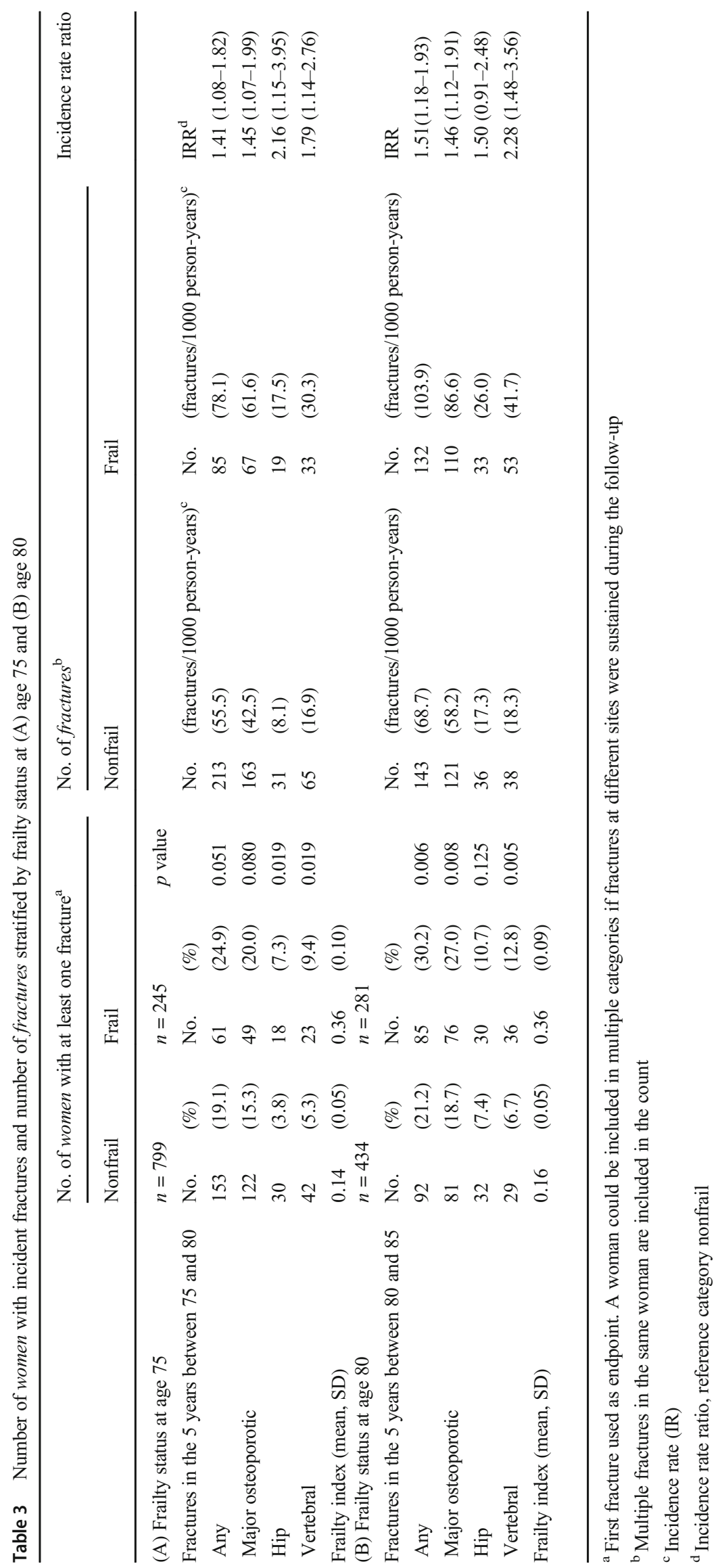




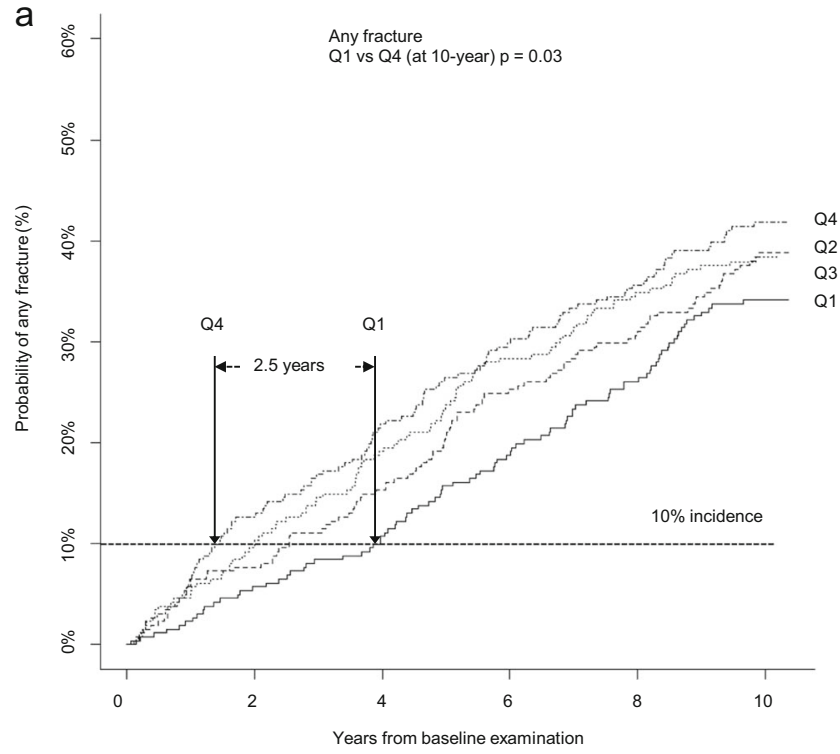

Fig. 2 Cumulative incidence of $\mathbf{a}$ any fracture and $\mathbf{b}$ hip fracture, stratified by quartiles of frailty at age 75 , calculated in the presence of the competing risk of death. Differences in cumulative incidence rates between Q1 and Q4 was tested using Gray's test. The graphs show that

much needed holistic approach to capturing fracture risk, making it a useful complement to existing assessment tools. Frailty is associated with fracture, and this study highlights that being frail presents a high risk of fracturing within the next 12-24 months. At entry into the study, frail women at the

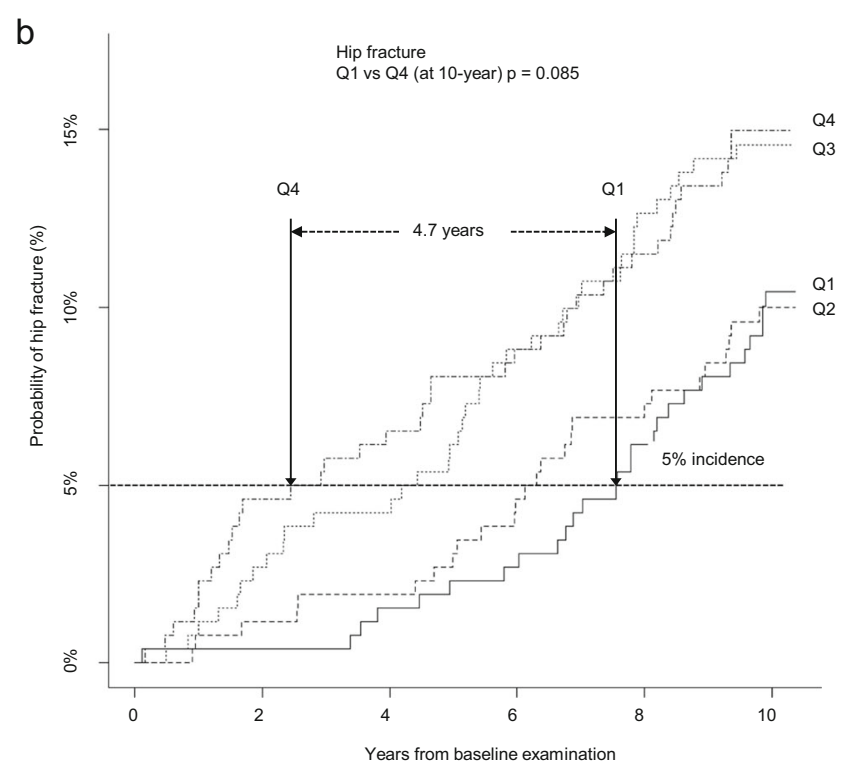

among the least frail (Q1), fracture accumulation occurs between 2.5 (any fracture) and 4.7 years (hip fracture) later, i.e., they remain fracture free for longer compared to the most frail women (Q4). "Frailty quartiles Q1 $(\leq 0.11)$, Q2 (0.12-0.16), Q3 (0.17-0.24), and Q4 $(\geq 25)$

age of 75 had a two to four times higher risk of hip fracture already within the first year. These women continue to be at higher risk over the next 2 years for hip fracture, MOF, and indeed any type of fracture. The observed higher fracture risk within the first year is in agreement with two other studies,

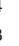
年
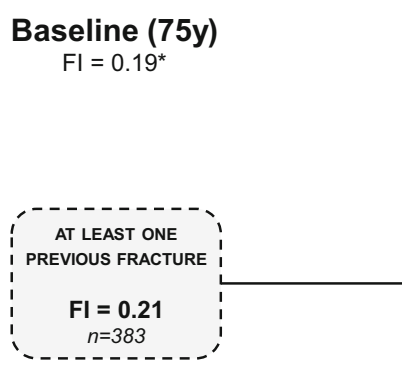

5-year follow-up (80y)

$\mathrm{FI}=0.24^{*}$ 10-year follow-up (85y)

$$
\mathrm{FI}=0.29^{*}
$$


albeit in younger individuals, confirming the value of frailty assessment by capturing health beyond chronological age [27, 28].

With increasing age, everyone becomes frailer, risk factors for fracture accumulate, and health status often rapidly changes. Since frailty is dynamic and accumulates at different rates, the value of an examination deflates over time. We showed that a higher fracture risk persisted over 5 years while after 10 years, frailty was no longer discriminative, because by age 85 , almost everyone is frail. Long-term projections are therefore less meaningful and frailty should be reassessed regularly. Further demonstrating this, when frailty was reassessed at age 80 , it again predicted high fracture risk within the short term. A number of studies have demonstrated association between frailty and fracture over 5-10 years [29-32] which is important in an epidemiological context, but given the short expected survival in the elderly, the immediate implications are more relevant. This association to imminent fracture risk has consequences for clinical decision making; most important is initiating interventions that have immediate effects, primarily to prevent falls leading to fracture, such as home environment adjustments, medication reconciliation, walking aids, and balance and strength training $[33,34]$. Delayed-effect interventions such as antiosteoporosis medication can be implemented in parallel. Frailty and fractures are related to one another bidirectionally. Our study shows not only that frailty leads to fractures but also that fracture is associated with higher frailty, which is in line with other studies [35]. This reflects what a critical element the musculoskeletal system plays in the frailty syndrome and, in addition, the functional decline and disability that results particularly from a hip fracture. Prompt interventions may prevent the downward spiral into progressing frailty and subsequent recurrence of fracture [36]. The benefit of secondary fracture prevention is clearly seen in our study; even in the event of a postmenopausal fracture between 50 and 75 , if a woman remains fracture free for 10 years, the trajectory of frailty will be similar to those who never fractured.

Not assessing frailty would be a missed opportunity in fracture prevention, since at age 75 , one in ten women from the frailest quartile will suffer a fracture after little more than a year. Those who were nonfrail remain fracture free longer, delaying hip fracture for almost 5 years and any fracture for two and half years. This observation highlights the variability in risk between fracture types and age; frailty predicts hip fracture at 75 , but less so after age 80 , a finding in part supported by others. While not completely comparable in terms of demographics and follow-up, in the Canadian Multicentre study (CaMos), Kennedy et al. find a similar loss of association among participants aged 65 and older [29]. The present study allows us to further understand the temporal relationships between fracture type and age; from age 80 , relative to nonfrail women, women who were frail had a larger increase in vertebral, shoulder, and pelvic fractures (data not shown) while the increase in hip and radius fractures was more pronounced among the nonfrail. Vertebral fracture was also associated with frailty. A novel finding was that even those who were only moderately frail (Q2) had double the risk of a vertebral fracture over 10 years. This is clinically relevant from two perspectives; (a) it emphasizes the utility of identifying prefrailty, and (b) since vertebral fractures are often symptom free and go undetected, it is possible that these "prefrail" women already have a vertebral fracture. Hence, it is a signal for investigation, and if warranted antiosteoporosis treatment, since if one has a vertebral fracture, one is likely to have another subsequent fracture [37].

We have shown that frailty captures multiple aspects of musculoskeletal aging in older women- osteoporosis, falls, and fracture - as well as mortality; therefore, it stands to reason that regular assessment of frailty has the capacity to be an additional tool in identifying those elderly at high risk of fracture $[15,16]$. We can also speculate that a rapid change in frailty status could further impact on fracture risk. This also means that interventions to reduce the risk can be initiated at an earlier stage with a person-centered approach. Focusing on hip fracture, in the elderly, most hip fractures result from a simple fall. The association between being frail and having a hip fracture within a year indicates that frailty encompasses many physical changes related to fall propensity such as impaired balance, sarcopenia, and musculoskeletal dysfunction. To be effective, a proactive health service is essential, involving communication between multiple caregivers, including primary care, physiotherapists, and clinicians, preferably before a first fracture has occurred and definitely in any postfracture program.

The strengths of this study includes firstly that the OPRA cohort was specifically designed to investigate bone health and therefore has detailed information on time to fracture and fracture site. The extensive follow-up time allowed exploration of the effects of existing and emerging frailty on fracture risk in a clinically meaningful context. Secondly, this study is performed in randomly selected, community-dwelling older women at an age where fracture incidence is accelerating, and the implications of suffering a fracture or becoming frailer are severe. Thirdly, the identical age of all the participants allows us to clearly demonstrate that frailty, which reflects biological age, is additive, beyond chronological age in terms of correctly predicting fracture risk. The data show that being frail "accelerates" the normal expectation of when a fracture will occur, i.e., $2-5$ years earlier. Being frail and a smoker confers an even higher risk of fracture. Fourthly, this study employed statistical modelling to account for the competing risk of death, a common problem in longitudinal studies of the elderly, therefore minimizing the potential for bias or overestimation. However, since Fine and Gray models give an approximate estimate of risk, the results should be interpreted with this in mind, and similarly that for all studies spanning decades, there is a loss of power from loss of participants beyond what is accountable by applying competing risk algorithms. 
Limitations are acknowledged. It is difficult to make direct comparisons with other studies due to the diversity of frailty instruments used in the literature. However, overall, the results are in general agreement, which is in line with the high redundancy, whereby one variable captures many. Furthermore, there may be bias towards the participants being healthier compared to the general population; however, this is inherent to all longitudinal studies of older people and may be beyond even what can be accounted for. Nevertheless, we were able to follow the increasing fracture burden in the population through the stepwise gradient of risk when transitioning into greater frailty. We also recognize that our findings pertain to the population of elderly women studied and may not be directly transferrable to other ages, ethnicities or to men.

To summarize, our study demonstrates that frailty is associated with imminent fracture risk, in particular hip fracture and other MOFs. Frailty needs to be reassessed regularly since health status can rapidly change in the elderly and with advancing age, which influence fracture risk. This knowledge is important, with the temporal aspects of fracture risk potentially having implications in the choice of treatment strategy.

Supplementary Information The online version contains supplementary material available at https://doi.org/10.1007/s00198-021-05886-7.

Acknowledgments Thanks are extended to funders, the research nurses, and data management at the Clinical and Molecular Osteoporosis Research Unit, Malmö, and to all the women who kindly participated in the study.

Funding Open access funding provided by Lund University. This work was supported by grants from the Swedish Research Council (201802981), Greta and Johan Kock Foundation, A. Påhlsson Foundation, A. Osterlund Foundation, H Järnhardt Foundation, King Gustav V 80-year fund, Swedish Rheumatism Foundation, Royal Physiographic Society Lund, Skåne University Hospital Research Fund, and the Research and Development Council of Region Skåne, Sweden. The funders had no role in study design, data collection and analysis, decision to publish, or preparation of the manuscript.

Availability of data and material Not applicable.

Code availability Not applicable.

\section{Declarations}

Compliance with ethical standards The study was performed in accordance with the Helsinki declaration and approved by the Lund University Ethical Review Board. Participants provided written consent.

Conflicts of interest The authors Patrik Bartosch, Linnea Malmgren, Jimmie Kristensson, Fiona McGuigan, and Kristina Åkesson declare no potential conflicts of interest according to ICMJE requirements with respect to the research, authorship, and/or publication of this article.

\section{References}

1. Hernlund E, Svedbom A, Ivergård M, Compston J, Cooper C, Stenmark J, McCloskey EV, Jönsson B, Kanis JA (2013) Osteoporosis in the European Union: medical management, epidemiology and economic burden. A report prepared in collaboration with the International Osteoporosis Foundation (IOF) and the European Federation of Pharmaceutical Industry Associations (EFPIA). Arch Osteoporos 8(1-2):136. https://doi.org/10.1007/ s11657-013-0136-1

2. Johnell O (1996) Advances in osteoporosis: better identification of risk factors can reduce morbidity and mortality. J Intern Med 239(4):299-304. https://doi.org/10.1046/j.1365-2796.1996. 429781000.x

3. von Friesendorff M, McGuigan FE, Wizert A, Rogmark C, Holmberg AH, Woolf AD, Akesson K (2016) Hip fracture, mortality risk, and cause of death over two decades. Osteoporos Int 27(10):2945-2953. https://doi.org/10.1007/s00198-016-3616-5

4. Jonsson E, Eriksson D, Akesson K, Ljunggren O, Salomonsson S, Borgstrom F, Strom O (2015) Swedish osteoporosis care. Arch Osteoporos 10:222. https://doi.org/10.1007/s11657-015-0222-7

5. Veronese N, Maggi S (2018) Epidemiology and social costs of hip fracture. Injury 49(8):1458-1460. https://doi.org/10.1016/j.injury. 2018.04.015

6. Margaras V (2019) European Parliament - Demographic trends in the EU regions. https://ec.europa.eu/futurium/en/system/files/ged/ eprs-briefing-633160-demographic-trends-eu-regions-final.pdf.

7. Milte R, Crotty M (2014) Musculoskeletal health, frailty and functional decline. Best Pract Res Clin Rheumatol 28(3):395-410. https://doi.org/10.1016/j.berh.2014.07.005

8. Clegg A, Young J, Iliffe S, Rikkert MO, Rockwood K (2013) Frailty in elderly people. Lancet (London, England) 381(9868): 752-762. https://doi.org/10.1016/s0140-6736(12)62167-9

9. Klotzbuecher CM, Ross PD, Landsman PB, Abbott TA 3rd, Berger M (2000) Patients with prior fractures have an increased risk of future fractures: a summary of the literature and statistical synthesis. J Bone Miner Res 15(4):721-739. https://doi.org/10.1359/jbmr. 2000.15.4.721

10. McGuigan FE, Bartosch P, Akesson KE (2017) Musculoskeletal health and frailty. Best Pract Res Clin Rheumatol 31(2):145-159. https://doi.org/10.1016/j.berh.2017.11.002

11. Rowe JW, Kahn RL (1997) Successful aging. Gerontologist 37(4): 433-440. https://doi.org/10.1093/geront/37.4.433

12. Bolland MJ, Jackson R, Gamble GD, Grey A (2013) Discrepancies in predicted fracture risk in elderly people. BMJ 346:e8669. https:// doi.org/10.1136/bmj.e8669

13. Kojima G (2016) Frailty as a predictor of fractures among community-dwelling older people: a systematic review and metaanalysis. Bone 90:116-122. https://doi.org/10.1016/j.bone.2016. 06.009

14. Chen KW, Chang SF, Lin PL (2017) Frailty as a predictor of future fracture in older adults: a systematic review and meta-analysis. Worldviews Evid-Based Nurs 14(4):282-293. https://doi.org/10. 1111/wvn. 12222

15. Bartosch P, McGuigan FE, Akesson KE (2018) Progression of frailty and prevalence of osteoporosis in a community cohort of older women-a 10-year longitudinal study. Osteoporos Int 29(10): 2191-2199. https://doi.org/10.1007/s00198-018-4593-7

16. Bartosch PS, Kristensson J, McGuigan FE, Akesson KE (2020) Frailty and prediction of recurrent falls over 10 years in a community cohort of 75-year-old women. Aging Clin Exp Res 32:22412250. https://doi.org/10.1007/s40520-019-01467-1

17. Gerdhem P, Ringsberg KA, Akesson K, Obrant KJ (2003) Influence of muscle strength, physical activity and weight on bone mass in a population-based sample of 1004 elderly women. 
Osteoporos Int 14(9):768-772. https://doi.org/10.1007/s00198003-1444-x

18. Gerdhem P, Magnusson H, Karlsson MK, Akesson K (2002) Ultrasound of the phalanges is not related to a previous fracture. A comparison between ultrasound of the phalanges, calcaneus, and DXA of the spine and hip in 75-year-old women. J Clin Densitom 5(2):159-166

19. Searle SD, Mitnitski A, Gahbauer EA, Gill TM, Rockwood K (2008) A standard procedure for creating a frailty index. BMC Geriatr 8:24. https://doi.org/10.1186/1471-2318-8-24

20. Rockwood K, Andrew M, Mitnitski A (2007) A comparison of two approaches to measuring frailty in elderly people. J Gerontol A Biol Sci Med Sci 62(7):738-743

21. Kojima G, Kendrick D, Skelton DA, Morris RW, Gawler S, Iliffe S (2015) Frailty predicts short-term incidence of future falls among British community-dwelling older people: a prospective cohort study nested within a randomised controlled trial. BMC Geriatr 15:155. https://doi.org/10.1186/s12877-015-0152-7

22. Gerdhem P, Akesson K (2007) Rates of fracture in participants and non-participants in the Osteoporosis Prospective Risk Assessment study. J Bone Joint Surg (Br) 89(12):1627-1631. https://doi.org/10. 1302/0301-620x.89b12.18946

23. Fine JP, Gray RJ (1999) A proportional hazards model for the subdistribution of a competing risk. J Am Stat Assoc 94(446): 496-509. https://doi.org/10.2307/2670170

24. Lydersen S (2015) Statistical review: frequently given comments. Ann Rheum Dis 74(2):323-325. https://doi.org/10.1136/ annrheumdis-2014-206186

25. Scrucca L, Santucci A, Aversa F (2007) Competing risk analysis using R: an easy guide for clinicians. Bone Marrow Transplant 40(4):381-387. https://doi.org/10.1038/sj.bmt.1705727

26. Scrucca L, Santucci A, Aversa F (2010) Regression modeling of competing risk using R: an in depth guide for clinicians. Bone Marrow Transplant 45(9):1388-1395. https://doi.org/10.1038/ bmt.2009.359

27. Albaba M, Cha SS, Takahashi PY (2012) The Elders Risk Assessment Index, an electronic administrative database-derived frailty index, can identify risk of hip fracture in a cohort of community-dwelling adults. Mayo Clin Proc 87(7):652-658. https://doi.org/10.1016/j.mayocp.2012.01.020

28. Tom SE, Adachi JD, Anderson FA Jr, Boonen S, Chapurlat RD, Compston JE, Cooper C, Gehlbach SH, Greenspan SL, Hooven FH, Nieves JW, Pfeilschifter J, Roux C, Silverman S, Wyman A, LaCroix AZ (2013) Frailty and fracture, disability, and falls: a multiple country study from the global longitudinal study of osteoporosis in women. J Am Geriatr Soc 61(3):327-334. https://doi.org/ 10.1111 /jgs. 12146

29. Kennedy CC, Ioannidis G, Rockwood K, Thabane L, Adachi JD, Kirkland S, Pickard LE, Papaioannou A (2014) A Frailty Index predicts 10 -year fracture risk in adults age 25 years and older: results from the Canadian Multicentre Osteoporosis Study (CaMos). Osteoporos Int 25(12):2825-2832. https://doi.org/10.1007/s00198014-2828-9

30. Zaslavsky O, Zelber-Sagi S, Gray SL, LaCroix AZ, Brunner RL, Wallace RB, O'Sullivan MJ, Cochrane B, Woods NF (2016) Comparison of frailty phenotypes for prediction of mortality, incident falls, and hip fracture in older women. J Am Geriatr Soc 64(9): 1858-1862. https://doi.org/10.1111/jgs.14233

31. Ensrud KE, Ewing SK, Taylor BC, Fink HA, Cawthon PM, Stone KL, Hillier TA, Cauley JA, Hochberg MC, Rodondi N, Tracy JK, Cummings SR (2008) Comparison of 2 frailty indexes for prediction of falls, disability, fractures, and death in older women. Arch Intern Med 168(4):382-389. https://doi.org/10.1001/ archinternmed.2007.113

32. de Vries OJ, Peeters GM, Lips P, Deeg DJ (2013) Does frailty predict increased risk of falls and fractures? A prospective population-based study. Osteoporos Int 24(9):2397-2403. https:// doi.org/10.1007/s00198-013-2303-Z

33. Sherrington C, Fairhall NJ, Wallbank GK, Tiedemann A, Michaleff ZA, Howard K, Clemson L, Hopewell S, Lamb SE (2019) Exercise for preventing falls in older people living in the community. Cochrane Database Syst Rev 1(1):Cd012424. https://doi.org/10. 1002/14651858.CD012424.pub2

34. Gillespie LD, Robertson MC, Gillespie WJ, Sherrington C, Gates S, Clemson LM, Lamb SE (2012) Interventions for preventing falls in older people living in the community. Cochrane Database Syst Rev (9):Cd007146. doi:https://doi.org/10.1002/14651858. CD007146.pub3

35. Li G, Papaioannou A, Thabane L, Cheng J, Adachi JD (2016) Frailty change and major osteoporotic fracture in the elderly: data from the global longitudinal study of osteoporosis in women 3-year Hamilton cohort. J Bone Miner Res 31(4):718-724. https://doi.org/ 10.1002/jbmr.2739

36. Toth E, Banefelt J, Åkesson K, Spångeus A, Ortsäter G, Libanati C (2020) History of previous fracture and imminent fracture risk in Swedish women aged 55 to 90 years presenting with a fragility fracture. J Bone Miner Res 35(5):861-868. https://doi.org/10. 1002/jbmr.3953

37. Johnell O, Oden A, Caulin F, Kanis JA (2001) Acute and long-term increase in fracture risk after hospitalization for vertebral fracture. Osteoporos Int 12(3):207-214. https://doi.org/10.1007/ s001980170131

Publisher's note Springer Nature remains neutral with regard to jurisdictional claims in published maps and institutional affiliations. 